Regine Helena Silva dos Fernandes VIEIRA ${ }^{1}$

Maylinque Albuquerque ATAYDE $^{2}$

Edirsana Maria Ribeiro de CARVALHO ${ }^{3}$

Fátima Cristiane Teles de CARVALHO ${ }^{4}$

Antonio Adauto FONTELES FILHO $^{1}$

\section{Correspondência para:}

Instituto de Ciências do Mar/Labomar/UFC Av. da Abolição, nº 3207, Meireles, 60165 081 Fortaleza/ CE, regine@labomar.ufc.br

Recebido para publicação: 03/04/2007 Aprovado para publicação: 13/12/2007

\title{
Contaminação fecal da ostra Crassostrea rhizophorae e da água de cultivo do estuário do Rio Pacoti (Eusébio, Estado do Ceará): Isolamento e identificação de Escherichia coli e sua susceptibilidade a diferentes antimicrobianos
}

\author{
1 - Instituto de Ciências do Mar-Labomar da Universidade Federal do Ceará, \\ Fortaleza-CE \\ 2 - Engenheira de Pesca, Fortaleza-CE \\ 3 - Mestranda do Curso Engenharia de Pesca da Universidade Federal do Ceará, \\ Fortaleza-CE \\ 4 - Doutoranda de Ciências Marinhas Tropicais/Labomar da Universidade Federal \\ do Ceará, Fortaleza-CE
}

\section{Resumo}

Este estudo objetivou avaliar a qualidade microbiológica da água do cultivo de ostras, do Estuário do Rio Pacoti, assim como a qualidade das ostras, através do Número Mais Provável (NMP) de coliformes totais $(\mathrm{Ct})$ e termotolerantes $(\mathrm{CT})$. Foram realizadas 15 colheitas, entre junho e novembro de 2006. A água do cultivo se manteve dentro dos limites permitidos pela Legislação vingente. O NMP de Ct/100 mL variou de $<1,8$ a 18.000 e de CT $/ 100 \mathrm{~mL}$ de $<1,8$ a 2.000, enquanto as ostras variaram os $\mathrm{Ct}$ e CT/g de $<1,8$ a 3.500 e $<1,8$ a 2.800, respectivamente. Vinte e cinco cepas de Escherichia coli isoladas da água de cultivo testadas quanto a susceptibilidade a alguns antimicrobianos se mostraram resistentes a ampicilina, nitrofurantoína, tetraciclina, sulfazotrin, ácido nalidíxico, ciprofloxacim, e a imipenem. Das ostras, somente quatro cepas, identificadas como E.coli mostraram-se resistentes a tetraciclina e a imipenem. Baseado nos valores obtidos de Ct e CT da amostra de água e ostras, foi possível constatar que: as águas do Rio Pacoti estão em boas condições segundo a legislação nacional; que a maioria das cepas de E. coli (59,43\%), isoladas da água do Rio Pacoti foi sensível aos antimicrobianos testados, exceção do imipenem para o qual as cepas de E.coli apresentaram alto percentual de resistência (80\%); a sensibilidade das cepas de E.coli isoladas das amostras de ostras apresentou-se alta à maioria dos antibióticos testados.

\section{Introdução}

O consumo de organismos aquáticos originários de águas contaminadas pode levar ao aparecimento de doenças transmitidas por alimentos (DTA) que podem ser causadas tanto por um agente infeccioso contaminante do alimento ingerido, como pela toxina por ele produzida no alimento. ${ }^{1}$

Organizações internacionais, tais como "Food and Drug Administration -
FDA", têm procurado através de princípios e normas, estabelecer o controle das condições sanitárias da água onde são cultivados os moluscos, objetivando garantir sua qualidade como alimento. No Brasil, a legislação pertinente, que estabelece critérios e normas de qualidade, com o objetivo de proteger e preservar sanitariamente as águas destinadas ao consumo e residuais, é bastante extensa e complexa. ${ }^{2}$

De acordo com Bastos et al. ${ }^{3}$, desde 
os primórdios da Microbiologia Sanitária existem dificuldades em se isolar organismos patogênicos de amostras ambientais, para tanto se sugere que a indicação de contaminação seja feita através de indicadores microbiológicos da presença de material fecal no meio ambiente. Os organismos que melhor têm cumprido este papel são as bactérias do grupo coliforme.

Vários fatores estão diretamente associados às doenças através da ingestão de ostras, uma vez que esses moluscos vivem geralmente em estuários e em áreas costeiras passíveis de poluição. A presença dos coliformes termotolerantes nas ostras indica que o alimento apresenta uma contaminação microbiana de origem fecal e, portanto, está em condições sanitárias insatisfatórias, podendo causar no consumidor o aparecimento de sintomas desagradáveis. ${ }^{4}$

Segundo Machado et al. ${ }^{5}$, em muitos países foi desenvolvido um conjunto de normas próprias para o processo de comercialização de moluscos devido aos riscos inerentes ao seu consumo. Essas normas são baseadas em análises microbiológicas da água do cultivo e/ou do tecido e líquido intervalvar.

Devido à grande importância microbiológica das ostras e sua relação com o meio ambiente, este trabalho tem como objetivo geral quantificar o Número Mais Provável (NMP) de Coliformes totais (Ct) e Coliformes Termotolerantes (CT) na ostra e na água do cultivo, assim como isolar e identificar cepas de Escherichia coli (E. coli) das amostras e verificar a susceptibilidade de algumas delas a antimicrobianos conhecidos comercialmente.

\section{Material e Método}

Durante 15 semanas, de junho a novembro de 2006, foram colhidas do estuário do Rio Pacoti (Figura 1), no município de Eusébio - Ceará, 15 amostras de ostras, Crassostrea rhizophorae e 15 de 1.000 $\mathrm{mL}$ da água do cultivo, em vidro de cor âmbar, esterilizado. Cada colheita de ostra constava de aproximadamente 10

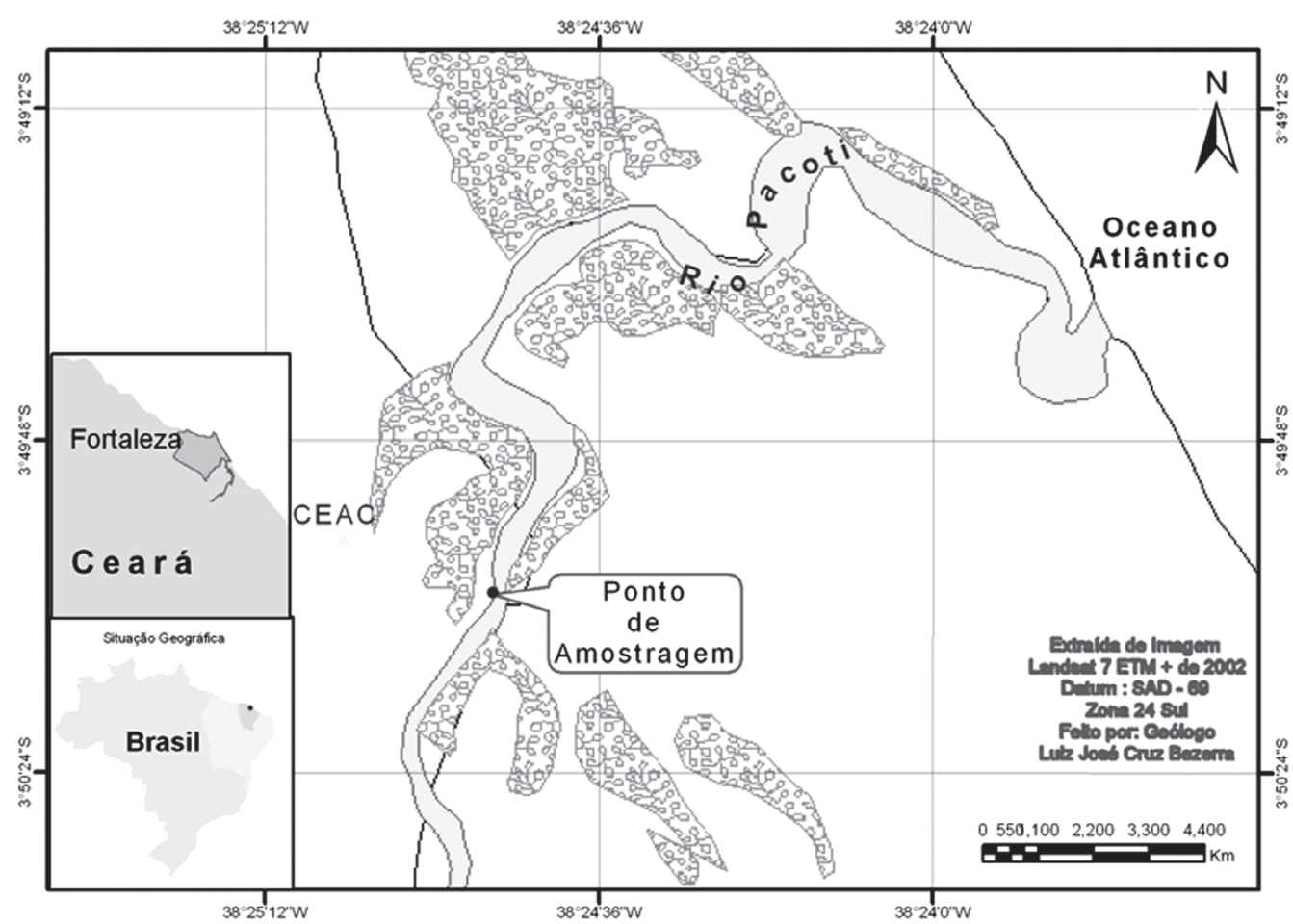

Figura 1 - Mapa de localização das amostras de ostra e água coletadas no Estuário do Rio Pacoti, Eusébio-CE, junho a novembro de 2006 
indivíduos, totalizando no final, a análise de 150 animais. As amostras foram acondicionadas em bolsa isotérmica, por um período de 1 hora, até chegarem ao Instituto de Ciências do Mar - LABOMAR, da Universidade Federal do Ceará, em Fortaleza/CE para a realização das análises microbiológicas.

As ostras, depois de passarem pelo processo de limpeza com lavagem em água corrente, foram abertas assepticamente e, destas, pesados $25 \mathrm{~g}$ de músculo e de líquido intervalvar. Essa mistura foi então homogeneizada com $225 \mathrm{~mL}$ de solução salina a $0,85 \%$ em liquidificador desinfectado. Essa preparação correspondeu a diluição $10^{-1} \mathrm{e}$ a partir delas foram feitas as demais diluições $\left(10^{-2}\right.$ a $\left.10^{-4}\right)$ usando-se também solução salina.

Em tubos com $10 \mathrm{~mL}$ de Caldo Lactose Bacto (Difco) esterilizados, contendo tubos de Durhan invertidos, foi depositado $1 \mathrm{~mL}$ da amostra de cada diluição de $10^{-1}$ a $10^{-4}$ para as ostras e, de $10^{-1}$ a $10^{-3}$, para a água, em série de cinco repetições. Os tubos foram então incubados a $35^{\circ} \mathrm{C} / 48 \mathrm{~h}$.

Dos tubos positivos foram retiradas alíquotas de $1 \mathrm{~mL}$ que foram depositadas em tubos contendo $10 \mathrm{~mL}$ do meio Bile Verde Brilhante- BVB (Difco) para Ct e de Caldo EC (Vetec) para CT, também contendo tubos de Durhan invertidos. Os tubos de caldo BVB foram incubados em estufa a $35^{\circ} \mathrm{C} / 48 \mathrm{~h}$, enquanto os de caldo $\mathrm{EC}$ foram incubados em banho-maria a $45^{\circ} \mathrm{C} / 24 \mathrm{~h}^{6}$.

Os resultados positivos de cada série foram anotados, para posterior consulta à tabela de Hoskins adaptada por Bacteriological Analytical Manual - BAM ${ }^{7}$.

Dos tubos positivos para CT foram retiradas alíquotas e com a ajuda de uma alça de níquel cromo foram estriadas placas de Agar Eosina Azul de Metileno (EMB) (Merck) e incubadas por 24 horas, a $37^{\circ} \mathrm{C}$.

As colônias características de E. coli, foram isoladas em tubos de ensaio contendo Agar Triptose Soja (TSA) (Merck) inclinado. Foram isoladas duas a três colônias características de E. coli de cada placa de EMB correspondente a cada tubo de CT positivo. Os tubos de TSA foram incubados em estufa a $37^{\circ} \mathrm{C} . / 24 \mathrm{~h}$ e, em seguida, as cepas foram observadas quanto a morfologia (bastonetes Gram negativos) em microscópio e testadas bioquimicamente pela bateria de testes do IMViC (Indol, Vermelho de Metila, Voges-Proskauer e Citrato) segundo Mehlman et al. ${ }^{7}$. As amostras de água tiveram suas temperaturas medidas no local de colheita com um termômetro de mercúrio da marca Inconterm. Os valores de $\mathrm{pH}$ foram verificados no laboratório através de um medidor de $\mathrm{pH}$ da marca Marconi-pa 200p e, para a salinidade, um refratômetro da marca Atago s/mill.

Foi usado o teste t para comparação do grau de contaminação por Ct e CT (tratamentos) em água e ostra (blocos) através do enfoque stepwise, tendo-se transformado os valores das variáveis NMP/100 mL (água) e NMP/g (ostra) por logaritimização, para miminizar a falta de homogeneidade da variância entre as observações dentro dos tratamentos e blocos.

Vinte e nove cepas de E. coli isoladas das amostras das ostras (4) e da água do cultivo (25), escolhidas ao acaso, foram semeadas em TSA e testadas quanto à sensibilidade aos seguintes antimicrobianos: ácido-nalidíxico (NAL), ampicilina (AMP), ciprofloxacim (CIP), imipenem (IPM), nitrofurantoína (NIT), sulfazotrim (SUT) e tetraciclina (TET). Culturas de E. coli, já identificadas, crescidas em TSA inclinado a $35^{\circ} \mathrm{C} / 24 \mathrm{~h}$, foram selecionadas e emulsionadas em solução salina estéril 0,85\% até se obter uma turvação equivalente à turbidez do tubo 0,5 na escala de McFarland. A comparação do tubo problema com o tubo turvo da Escala McFarland foi feita através da ajuda de um espectofôtometro de Micronal B542. Dos tubos problema foram semeadas placas contendo Ágar Mueller-Hinton-Difco ( $\mathrm{MH})$, com o auxílio de um swab estéril umedecido, removendose o excesso nas paredes do tubo. Em seguida, os discos de antimicrobianos foram depositados, com o auxilio de uma pinça 
estéril na superfície do ágar. As placas foram então incubadas em estufa a $35^{\circ} \mathrm{C} / 24 \mathrm{~h} \mathrm{e}$ logo após esse período, foram realizadas as medições dos halos utilizando-se um paquímetro. ${ }^{8}$

\section{Resultados e Discussão}

O NMP de Ct das amostras de água e das ostras variou de $<1,8$ a $1,8 \times 10^{4} / 100$ $\mathrm{mL}$ e de $<1,8$ a $3,5 \times 10^{3} / \mathrm{g}$, respectivamente, enquanto que os valores para CT nas amostras de água apresentaram variação de $<1,8$ a $2,0 \times 10^{3} / 100 \mathrm{~mL}$ e nas amostras de ostras de $<1,8$ a 2, $8 \times 10^{3} / \mathrm{g}$ (Tabela 1 ).

A Resolução vigente $n^{\circ} 12$ da Agência Nacional de Vigilância Sanitária ${ }^{1}$ não limita o grupo dos $\mathrm{C}$, nem oferece critérios para a avaliação de moluscos consumidos in natura, contemplando somente moluscos bivalves cozidos, industrializados resfriados ou congelados, quando estabelece um limite para coliformes termotolerantes, que é de $5 \mathrm{X} 10$ quando estocado em $45^{\circ} \mathrm{C} / \mathrm{g}$.
Anteriormente, a Portaria $\mathrm{n}^{\circ} 451^{9}$ especificava limites de NMP para coliformes termotolerantes de $10^{2} / \mathrm{g}$ para pescados consumidos crus (item IV, alínea a) e, sendo as ostras geralmente consumidas cruas, tornase incompreensível sua revogação, uma vez que a Resolução n ${ }^{\circ} 12$ da ANVISA ${ }^{1}$ dificulta a avaliação da qualidade microbiológica do alimento em questão.

Como a Legislação Brasileira não é satisfatória para que se obtenha uma efetiva avaliação microbiológica de moluscos bivalves, podem-se submeter os valores encontrados neste estudo a padrões internacionais, como o The European Union Shellfish Quality Assurance Programme (EUSQAP) $^{10}$, que classifica os moluscos bivalves em três classes: A, B e C. Para cada classe é permitida uma quantidade de coliformes termotolerantes por $100 \mathrm{~g}$ de massa visceral e de líquido intervalvar. Para a classe $\mathrm{A}$, a tolerância é de $<300 \mathrm{CT} / 100$ $\mathrm{g}$, na classe B $90 \%$ das amostras não podem exceder a $6.000 \mathrm{CT} / 100 \mathrm{~g}$ e na classe $\mathrm{C}$,

Tabela 1 - Número Mais Provável (NMP) de coliformes totais (Ct) e termotolerantes (CT) de água de cultivo e de ostra Crassostrea rhizophorae, do Estuário do Rio Pacoti, Eusébio-CE, junho a novembro de 2006

\begin{tabular}{cccccc}
\hline \multirow{2}{*}{ Colheita } & \multicolumn{2}{c}{$\mathrm{Ct}$} & \multicolumn{2}{c}{$(\mathrm{CT})$} & Pluviometria* \\
\cline { 2 - 6 } & $\begin{array}{c}\text { Água } \\
(\mathrm{NMP} / 100 \mathrm{~mL})\end{array}$ & $\begin{array}{c}\text { Ostra } \\
(\mathrm{NMP} / \mathrm{g})\end{array}$ & $\begin{array}{c}\text { Ostra } \\
(\mathrm{NMP} / 100 \mathrm{~mL})\end{array}$ & $\begin{array}{c}\text { (milímetro) } \\
(\mathrm{NMP} / \mathrm{g})\end{array}$ \\
\hline 1 & $3,4 \times 10^{2}$ & $3,5 \times 10^{3}$ & $1,1 \times 10^{2}$ & $2,8 \times 10^{3}$ & 0 \\
3 & $2,8 \times 10^{3}$ & $4,9 \times 10^{1}$ & $4,7 \times 10^{2}$ & $3,3 \times 10^{1}$ & 0 \\
4 & $3, .5 \times 10^{3}$ & $2,2 \times 10^{1}$ & $2,1 \times 10^{2}$ & $2,2 \times 10^{1}$ & 0 \\
5 & $0,4 \times 10^{2}$ & $2,1 \times 10^{2}$ & $4,0 \times 10^{1}$ & $3,3 \times 10^{1}$ & 0 \\
6 & $0,4 \times 10^{2}$ & $4,5 \times 10^{1}$ & $4,0 \times 10^{1}$ & $<1,8 \times 10^{0}$ & 0 \\
7 & $4,5 \times 10^{1}$ & $7,9 \times 10^{1}$ & $<1,8 \times 10^{0}$ & $<1,8 \times 10^{0}$ & 0 \\
8 & $2,0 \times 10^{2}$ & $<1,8 \times 10^{0}$ & $2,0 \times 10^{1}$ & $<1,8 \times 10^{0}$ & 0 \\
9 & $4,0 \times 10^{1}$ & $0,2 \times 10^{1}$ & $4,0 \times 10^{1}$ & $<1,8 \times 10^{0}$ & 0 \\
10 & $1,8 \times 10^{4}$ & $3,3 \times 10^{1}$ & $2,0 \times 10^{3}$ & $1,7 \times 10^{1}$ & 12 \\
11 & $1,3 \times 10^{2}$ & $<1,8 \times 10^{0}$ & $1,3 \times 10^{2}$ & $<1,8 \times 10^{0}$ & 0 \\
12 & $4,5 \times 10^{1}$ & $<1,8 \times 10^{0}$ & $<1,8 \times 10^{0}$ & $<1,8 \times 10^{0}$ & 0 \\
13 & $2,0 \times 10^{1}$ & $7,8 \times 10^{0}$ & $<1,8 \times 10^{0}$ & $<1,8 \times 10^{0}$ & 0 \\
14 & $<1,8 \times 10^{0}$ & $0,4 \times 10^{1}$ & $<1,8 \times 10^{0}$ & $0,4 \times 10^{1}$ & 0 \\
15 & $4,5 \times 10^{1}$ & $<1,8 \times 10^{0}$ & $4,5 \times 10^{1}$ & $<1,8 \times 10^{0}$ & 0
\end{tabular}

*Dados formecidos pela Fundação Cearense de Metereologia e Recursos Hídricos (FUNCEME) para o dia em que foi feita a colheita 
não podem exceder a $60.000 \mathrm{CT} / 100 \mathrm{~g}$. Baseado nas normas deste Programa, nove das amostras de ostra estariam classificadas na classe $A$, cinco na classe $B$ e uma na classe C (Tabela 1).

As análises microbiológicas da água seguiram a Resolução n 357 de 2005, do Conselho Nacional do Meio Ambiente ${ }^{11}$, que determina que para o cultivo de moluscos bivalves destinados à alimentação humana, a média geométrica da densidade de coliformes termotolerantes, de um mínimo de 15 amostras colhidas no mesmo local, não deverá exceder 43/100 mL. De acordo com essa Resolução, a média geométrica apresentou-se satisfatória com um valor de 27, condizente para águas Classe 1 (águas salinas destinadas à proteção das comunidades aquáticas, à aqüicultura e à atividade de pesca).

Os testes estatísticos revelaram que a água de cultivo se apresentou mais contaminada do que as ostras, independente do fator de contaminação (coliformes totais ou coliformes), com significância estatística ao nível de 5\%, para GL $=58\left(\mathrm{t}_{\mathrm{crt}}=2,744\right.$; $\mathrm{P}=0,0081)$. No entanto, quando se considera o tipo de coliforme, verificou-se que não há diferença entre as intensidades de contaminação por coliformes totais ou por coliformes termotolerantes, como indicou a ausência de significância estatística entre tratamentos ao nível de 5\%, para GL $=58\left(\mathrm{t}_{\mathrm{crtt}}=1,546 ; \mathrm{P}=0,1275\right)$.

$\mathrm{O}$ meio urbano dá origem a várias impurezas, tais como, poluentes atmosféricos carreados pela chuva, poeira e lixo, erosão do solo, uso de defensivos e fertilizantes em jardins, além de ligações clandestinas de esgotos às galerias pluviais que favorecem a presença de microrganismos patógenos ${ }^{12}$. Esses poluentes caem em corpos d'água que, por sua vez, podem poluir criadouros nativos de moluscos. Como esses animais são filtradores e bioacumuladores de microrganismos, sua microbiota está diretamente relacionada ao ambiente do qual eles se originam. ${ }^{13}$

As medidas de salinidade, temperatura, $\mathrm{pH}$ estão dispostas na tabela
2. A salinidade variou entre $10 \%$ (mínimo) e $40 \%$ (máximo). Os valores observados da temperatura variaram entre $25^{\circ} \mathrm{C}$ e $30,5^{\circ} \mathrm{C}$ e os valores de $\mathrm{pH}$ ficaram entre 7,2 e 8,2.

Escherichia coli é um dos patógenos de maior importância quando se deseja constatar contaminação por esgotos. Todavia, à semelhança das demais bactérias, ela necessita de condições favoráveis para se multiplicar. A água do mar, devido a grandes concentrações de sais, pode funcionar como fator limitante para multiplicação de E. coli ${ }^{14}$, fato que pôde ser comprovado nessa pesquisa, uma vez que, a partir da $6^{\circ}$ colheita, ocorreu um acréscimo considerável nos valores de salinidade. De acordo com a Resolução n ${ }^{\circ} 357$ de 2005 do Conselho Nacional do Meio Ambiente ${ }^{11}$, que classifica as águas em salobras $(0,5$ a $30 \%$ o $)$ e salinas $(>30 \%$ ), para os valores encontrados neste estudo, as amostras de água, em sua maioria, foram classificadas como salinas (Tabela 2).

Os coliformes têm pouca tolerância à salinidade das águas do mar, portanto sua detecção nesse ambiente denota uma descarga recente e constante de matéria fecal, sendo importante constatar-se a relação inversamente proporcional entre salinidade e numero de coliformes. Sendo o sal tóxico para os coliformes, existe a eliminação de $90 \%$ da população de E. coli em poucas horas ou em minutos, quando essa bactéria entra em contato com águas marinhas. ${ }^{15}$

$\mathrm{O}$ maior valor encontrado para $\mathrm{Ct}$ e CT na água do cultivo (Tabela 1) coincidiu com o dia em que ocorreu precipitação pluviométrica, comprovando que as chuvas interferem no índice de qualidade microbiológica da água, pois estas têm a capacidade de arrastar esgotos e resíduos sólidos para os cursos d'água que, por sua vez, afluem para o mar. ${ }^{16,17}$

A temperatura da água do cultivo durante todo o experimento encontrou-se favorável ao crescimento das bactérias mesófilas e, de acordo com Gauthier, Breittmayer e Braux $^{18}$, o risco de poluição de águas marinhas por E. coli e por extensão, pelas enterobactérias patogênicas ao ser humano, é muito mais acentuado em águas 
Tabela 2 - Parâmetros físico-químicos (salinidade, temperatura e $\mathrm{pH}$ ) da água de cultivo de ostras Crassostrea rhizophorae do Estuário do Rio Pacoti-CE, junho a novembro de 2006

\begin{tabular}{cccc}
\hline Colheitas & Salinidade (\%o) & Temperatura $\left({ }^{\circ} \mathrm{C}\right)$ & $\mathrm{pH}$ \\
\hline 1 & 10 & 28,0 & 7,65 \\
2 & 10 & 27,0 & 7,40 \\
3 & 11 & 26,5 & 7,76 \\
4 & 13 & 26,0 & 7,88 \\
5 & 17 & 25,0 & 7,74 \\
6 & 35 & 27,0 & 8,24 \\
7 & 32 & 25,0 & 7,76 \\
8 & 35 & 28,0 & 7,55 \\
9 & 37 & 30,5 & 7,76 \\
10 & 37 & 27,0 & 7,20 \\
11 & 38 & 28,0 & 7,98 \\
12 & 38 & 28,5 & 7,74 \\
13 & 38 & 29,0 & 7,51 \\
14 & 39 & 29,5 & 7,30 \\
15 & 40 & 28,0 & 7,80 \\
\hline
\end{tabular}

quentes e ricas em matéria orgânica.

De acordo com Rozen e Belkin ${ }^{19}$, o $\mathrm{pH}$ da água do mar se situa normalmente entre 7,5 e 8,5 e é influenciado pela temperatura, pressão e atividades fotossintéticas e respiratórias dos microrganismos. Segundo os autores, um $\mathrm{pH}$ ácido, em torno de 5,0, favorece à sobrevivência da E. coli, ao passo que o pH da água do mar, em torno de 8,0, contribui para um efeito deletério na sobrevivência da bactéria. Os dados de $\mathrm{pH}$ encontrados nesta pesquisa estão todos de acordo com a legislação vigente ${ }^{11}$, tanto para águas salobras como salinas.

Os dados relativos à sensibilidade das 25 cepas de E. coli, isoladas do músculo e do líquido intervalvar da ostra (Figura 2) aos antimicrobianos, ácido nalidíxico, ciprofloxacim e nitrofurantoína são semelhantes aos encontrados por Morelli ${ }^{2}$.

As cepas isoladas a partir da água do cultivo apresentaram um percentual maior de resistência aos antimicrobianos imipenem $(80 \%)$ e a ampicilina (48\%) e um percentual de resistência menor aos antimicrobianos: tetraciclina $(24 \%)$, sulfaxotrim $(20 \%)$, ácido nalidíxico $(16 \%)$, ciprofloxacim $(8 \%)$ e nitrofurantoína (4\%).

Uma pesquisa realizada por Cardonha et al. ${ }^{20}$ em três praias de Natal confirmou cepas de E. coli, isoladas da água do mar, resistentes a tetraciclina, ampicilina e nitrofurantoína, corroborando com os dados desta pesquisa, uma vez que, foram confirmadas cepas resistentes a esses antimicrobianos, mesmo em menor percentual. $\mathrm{Na}$ mesma pesquisa, os autores identificaram sensibilidade nas cepas de E. coli, isoladas de águas do mar, de 100\% ao imipenem e a ciprofloxacim. Vasconcelos ${ }^{21}$, ao estudar duas praias de Fortaleza, isolou cepas de E. coli de água do mar que também foram 100\% sensíveis aos mesmos antimicrobianos, ao passo que, na presente pesquisa verificou-se uma alta resistência ao imipenem e uma discreta resistência ao ciprofloxacim, porém a constatação deste fato é preocupante vez que ambos os antimicrobianos são usados, primariamente, em hospitais.

Somente quatro cepas de E. coli, isoladas do músculo e do líquido intervalvar da ostra, provenientes de quatro amostras, 


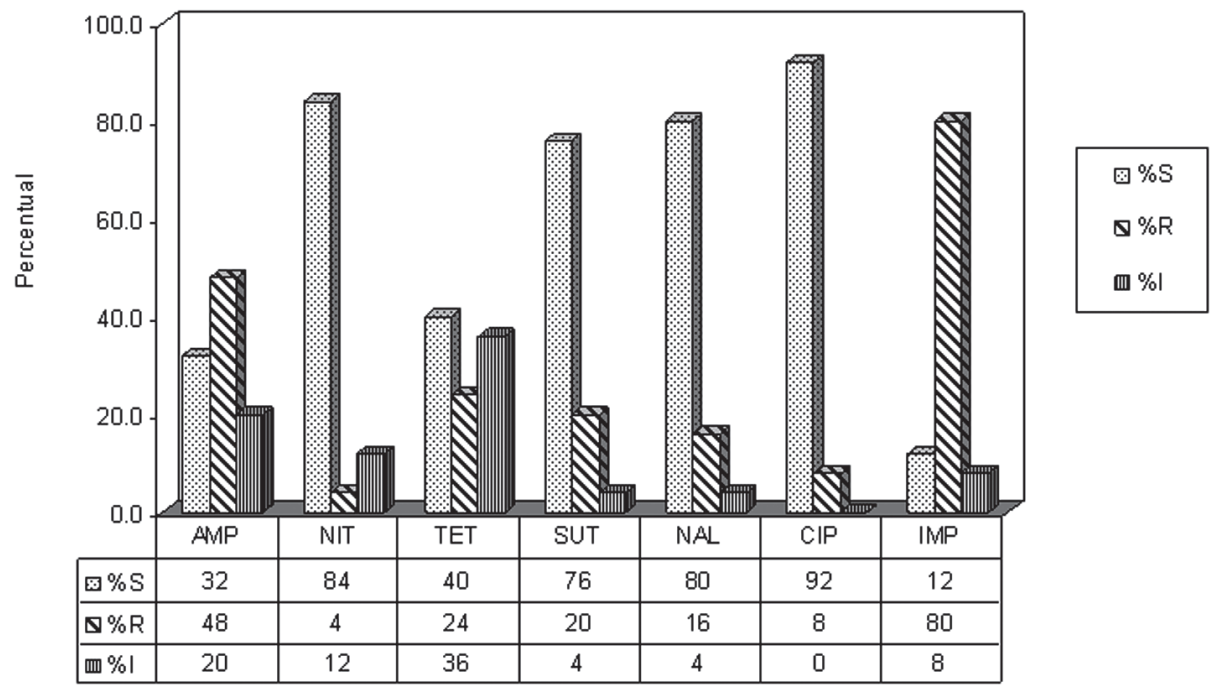

Figura 2 - Susceptibilidade a antimicrobianos das cepas de Escherichia coli isoladas da água de cultivo das ostras Crassostrea rhizophorae, do Estuário do Rio Pacoti, Eusébio-CE, de junho a novembro de 2006. $(\mathrm{AMP}=$ Ampicilina; $\mathrm{NIT}=$ Nitrofurantoína; $\mathrm{TET}=$ Tetraciclina; $\mathrm{SUT}=$ sulfazotrim; $\mathrm{NAL}=$ Ácido Nalidíxico; $\mathrm{CIP}=$ Ciprofloxacim; IMP = Imipenem)

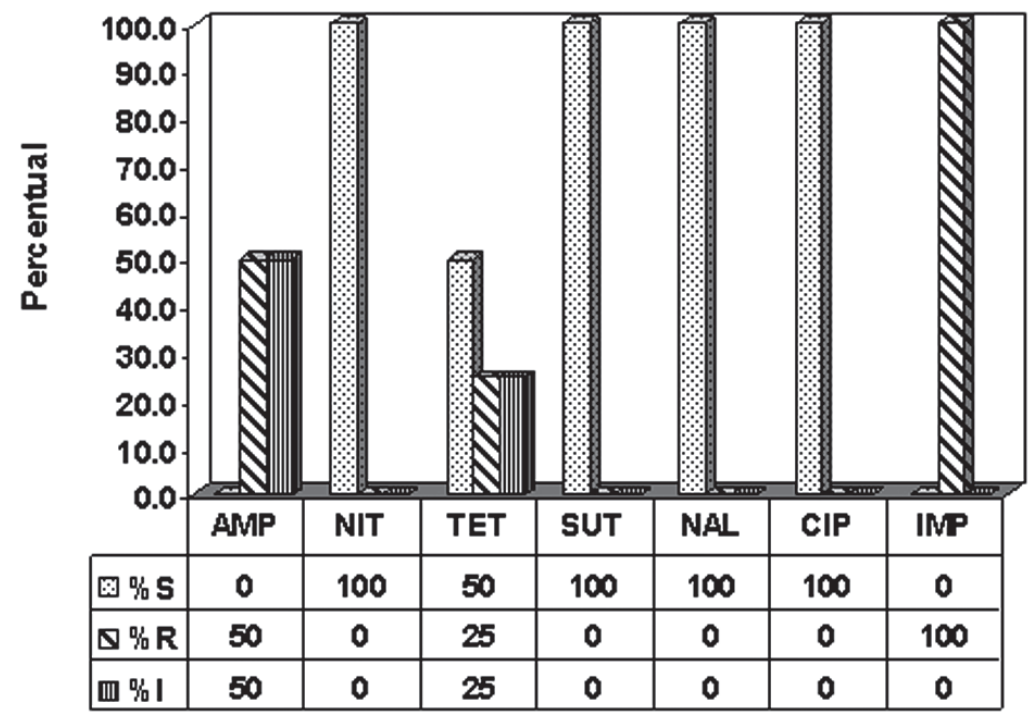

\begin{tabular}{|l|}
\hline $\boldsymbol{Q} \% \mathrm{~S}$ \\
$\mathbf{Q} \% \mathrm{R}$ \\
$\mathrm{m} \% \mathrm{I}$
\end{tabular}

Figura 3 - Susceptibilidade a antimicrobianos das cepas de Escherichia coli isoladas de ostras Crassostrea rhizophorae, do Estuário do Rio Pacoti, Eusébio-CE, de junho a novembro de 2006. (AMP=Ampicilina; $\mathrm{NIT}=$ Nitrofurantoína; TET = Tetraciclina; SUT = sulfazotrim; NAL = Ácido Nalidíxico; $\mathrm{CIP}=$ Ciprofloxacim; IMP = Imipenem)

puderam ser testadas em relação à sensibilidade a antimicrobianos (Figura 3).

As cepas de E. coli isoladas a partir das amostras do músculo das ostras (com líquido intervalvar) apresentaram um percentual de resistência de $100 \%$ ao imipenem, $25 \%$ a tetraciclina e nenhuma resistência a ampicilina, enquanto que $100 \%$ das amostras se mostraram sensíveis aos antimicrobianos, nitrofurantoína, sulfazotrim, ácido nalidíxico e ciprofloxacim.

Morelli et al. ${ }^{2}$ isolaram E.coli de ostras comercializadas em duas barracas da Praia do Futuro, Fortaleza-Ceará, e as cepas apresentaram resistência a ampicilina, discordando dos dados observados nesta pesquisa. Outra discordância é o fato das cepas de E. coli 
isoladas no presente trabalho se mostrarem 100\% resistentes ao imipenem, contrastando com as do trabalho anteriormente citado.

A resistência crescente das bactérias patogênicas aos antimicrobianos tem causado preocupação ao mundo científico. É dito que o uso generalizado de agentes antimicrobianos na produção animal pode promover o desenvolvimento de bactérias resistentes ou de genes de resistência que possam ser transferidos para bactérias causadoras de doenças ao ser humano. ${ }^{22}$ A maioria das cepas de E. coli não causa doenças ao ser humano, mas algumas possuem fatores de virulência e podem ser uma ameaça à vida. ${ }^{23,24}$

\section{Conclusões}

Segundo os padrões da Comunidade Européia para coliformes termotolerantes em ostras, as amostras desse molusco e da água de cultivo no estuário do Rio Pacoti estão em boas condições para o consumo.

A sensibilidade das cepas de E.coli isoladas das amostras de ostras apresentouse alta à maioria dos antibióticos testados. O fato de nenhuma das cepas testadas ter apresentado susceptibilidade ao imipenem reforça a preocupação com o uso indiscriminado de antibióticos em ambientes aquáticos, vez que os efluentes terminam desaguando em áreas de criação de ostras o que pode induzir à resistência na microbiota dos moluscos.

Fecal contamination of the mangrove oyster Crassostrea rhizophorae and the cultivation water at the river pacoti estuary (Eusébio - Ceará State) : Identification and isolation of Escherichia coli and its susceptibility to different antimicrobians

\begin{abstract}
This study has been designed to assess the microbiological quality of oyster Crassostrea rbizophorae and of the water used in farms located at the Pacoti River estuary, Ceará State, by means of the MPN of total coliforms (Ct) and thermtolerant coliforms (CT). The database consisted of 15 samples collected from June to November, 2006. The water was kept within the limits set up by the current legislation. MPN values were in the ranges of $<1.8-$ 18,000 Ct per $100 \mathrm{ml}$ and $<1.8-2,000 \mathrm{CT}$ per $100 \mathrm{ml}$, for the water, and $<1.8-3,500 \mathrm{Ct}$ per gram and $<1.8-2,800 \mathrm{CT}$ per gram for the oyster itself. Twenty-five strains isolated from the cultivation water and identified as Escherichia coli were tested for susceptibility to a few antimicrobians and proved resistant to ampicillin, nitrofurantoin, tetracycline, sulfazotrin, nalidixic acid, ciprofloxacin and imipenem. From the oysters, four strains were identified as E. coli and proved resistant to tetracycline and imipenem. From the afore-mentioned results, it can be concluded that: Pacoti River waters have received a clean bill of health according to the national legislation; the majority of water-isolated E.coli strains (59.43\%) were sensitive to the currently used antimicrobians, except for imipenem to which $80 \%$ of the identified E. coli strains proved resistant; sensitivity of the oysterisolated E. coli strains was found to be high to most of the tested antimicrobians. In all, it is suggested that more clear management measures be made available so as to allow for microbiological quality evaluation of raw-consumed mollusks.
\end{abstract}

Key words: Oyster.

Escherichia coli.

Susceptibility to antimicrobians. 


\section{Referências}

1 AGÊNCIA NACIONAL DE VIGILÂNCIA SANITÁRIA. Resolução - RDC № 12, de 2 de janeiro de 2001. Regulamento técnico sobre os padrões microbiológicos para alimentos. Diário Oficial [da] República Federativa do Brasil, Brasília, DF, 10 jan. 2001. Disponível em: $<$ http://www.anvisa.gov.br/legis/resol/12 $01 \mathrm{rdc} . \mathrm{htm}>$. Acesso em: 6 jan. 2007.

2 MORELLI, A. M. F. et al. Indicadores de contaminação fecal para ostra-do-mangue (Crassostrea rhizophorae) comercializada na Praia do Futuro, Fortaleza, Ceará. Higiene Alimentar, v. 17, n. 113, p. 81-88, 2003.

3 BASTOS, R. K. S. et al. Coliformes como indicadores da qualidade da água: alcance e limitações. In: CONGRESO INTERAMERICANO DE INGENERÍA SANITARIA Y AMBIENTAL, 27., 2000, Porto Alegre. Anais... Rio de Janeiro: Associação Brasileira de Engenharia Sanitária e Ambiental, 2000. [t.4], p. 1-11.

4 SILVA, A. I. M. et al. Bacteria of fecal origin, in mangrove oysters (Crassostrea rhizophorae) in the Cocó River estuary, Ceará State, Brazil . Brazilian Journal of Microbiology, v. 35, n. 1-2, p. 126-130, 2004.

5 MACHADO, I. C. et al. Estudo da ocorrência de contaminação orgânica no estuário da Cananéia, como subsídio para a extração, manejo e cultivo da ostra do mangue (Crassostrea brasiliana). 2 - Análise da ostra (tecidos moles e líquido intravalvar). Higiene Alimentar, v. 15, n. 83, p. $44-48,2001$.

6 FENG, P.; WEAGANT, S. D.; GRANT, M. A. Enumeration of Escherichia coli and the Coliform Bacteria In: FOOD and DRUG ADMINISTRATION. Center for food safety and applied nutrition. Bacteriological analytical manual. 8th ed. 1998. Cap. 4. Disponível em: < http://www.cfsan.fda.gov/ ebam/ bam-4.html >. Acesso em: 19 maio 2006.

7 MEHLMAN, I. J.; ANDREWS, W. II.; WENTZ, V. A. Coliform bacteria. In: Association of Official Analytical Chemists. Bacteriological analytical manual. $6^{\text {th }} \mathrm{ed}$. Arlington, 1984. p. 5.01-5.07.

8 KOLETAR, S. L. Escherichia coli. In: MAHON, C. R.; MANUSELIS, G. JR. (Ed.).Textbook diagnostic microbiology. Philadelphia: Saunders Company, 1995. cap. 3, p. 50-96.

9 BRASIL. Ministério da Saúde. Portaria MS no 451, de 19 de setembro de 1997. Aprova o regulamento técnico princípios gerais para estabelecimento de critérios e padrões microbiológicos para alimentos. Diário Oficial [da] República Federativa do Brasil, Brasília, DF, 27 set. 1997. Disponível em: <http: www. anvisa.gov.br/ legis/ portarias 451 - 97. htm >.Acesso em: 10 jun. 2002.

10 RODGERS, C. J. The NSW Shellfish Quality Assurance Program: an operational review. Sydney: Safe Food Production NSW, 2001. 146 p.

11 CONSELHO NACIONAL DO MEIO AMBIENTE.
Resolução n 357 de 17 de março de 2005. Dispõe sobre a qualidade dos corpos de água e diretrizes ambientais para o seu enquadramento, bem como estabelece as condições e padrões de lançamentos de efluentes e dá outras providências. Diário Oficial [da] República Federativa do Brasil, Brasília, DF. Disponível em: < http://www.mma.gov.br/conama/res/res05/ res35705.pdf. > Acesso em: 6 jan. 2007.

12 MOTA, S. Preservação dos recursos hídricos. Rio de Janeiro: Associação Brasileira dos Engenheiros Sanitaristas, 1988. 222 p.

13 ZAMARIOLI, L. A. et al. Estudo microbiológico do tecido mole de bivalves Crassostrea brasiliana, Perna perna e Mytella falcata recém coletados nos bancos naturais do litoral da baixada santista. São Paulo: Secretaria de Estado da Saúde, 1997. Relatório Apresentado ao Grupo de Vigilância Sanitária DIR XIX.

14 VIEIRA, R. H. S. F. et al. Análise experimental sobre a viabilidade de Escherichia coli em água do mar. Arquivos de Ciências do Mar, v. 34, p. 43-48, 2001.

15 HAGLER, A. N.; HAGLER, L. C. S. M. Indicadores Microbiológicos de qualidade sanitária, In: ROITMAN, I.; TRAVASSOS, L. R.; AZEVEDO, J. L. (Ed.). Tratado de microbiologia. São Paulo: Manole, 1988. v. 1 p. 88-96.

16 LIZÁRRAGA-PARTIGA, M. L.; CÁRDENAS, G. V. Influence of water circulation on marine and faecal bacteria in a mussel growing area. Marine Pollution Bulletin, v. 32, n. 2, p. 196-201, 1996.

17 SALATI FILHO, E. Condicionantes do desenvolvimento sustentável do litoral norte Paulista: o exemplo da bacia do córrego de Lagoinha UbatubaSP. 2001.148 f. Tese (Doutorado) - Universidade Estadual Paulista Julio de Mesquita Filho, Rio Claro, São Paulo, 2001.

18 GAUTHIER, M. J.; BREITTMAYER, V. A.; BRAUX, A. S. Expression génique cez es bactéries enatériques dans les conditions marines. In: PUNE/OMS-Cicles biogéoquimiques de pollants spécifiques (Avtivité K): survie des pathogenes. Rapports finaux sur les projets de recherche (1992-1993). Athens: UNEP, 1993. (MAP technical reports series n. 76).

19 ROZEN, Y.; BELKIN, S. Survival of enteric bacteria in seawater. FEMS Microbiology Reviews, v. 725, p. 1 17, 2001.

20 CARDONHA, A. M. S. et al. Fecal pollution in water from storm sewers and adjacent seashores in Natal, Rio Grande do Norte, Brazil. International Microbiology, v. 7, n. 3, p. 213-218, 2004.

21 VASCONCELOS, R.H. Balneabilidade das praias de Iracema e Náutico (Fortaleza - Ceará) e pesquisa de cepas de Escherichia coli patogênicas em suas águas. 2005. 31 f. Monografia - Universidade Federal do Ceará, Fortaleza, 2005.

22 WEGENER, H. C.; BAGER, F.; ARESTRUP, F. M. Vigilância da resistência aos antimicrobianos no homem, 
nos produtos alimentares e no gado da Dinamarca. Surviellance Report, v. 2, n. 3, p. 17-19, 1997.

23 GRANT, S. J. et al. Prevalence of enterohemorrhagic Escherichia coli in raw and treated municipal sewage. Applied and Environmental Microbiology, v. 62, n. 9, p. 3466-3469, 1996

24 TÔRRES, R. C. O. Escherichia coli. In: VIEIRA, R. H. S. F. (Coord.). Microbiologia, higiene e qualidade do pescado: teoria e prática. São Paulo: Varela, 2004. 